\title{
Effects of fatty acids on inducing endoplasmic reticulum stress in bovine mammary epithelial cells
}

\author{
Mst Mamuna Sharmin, ${ }^{1}$ Moeko Mizusawa, ${ }^{2}$ Satoko Hayashi, ${ }^{1}$ Wataru Arai, ${ }^{2}$ Shotaro Sakata, ${ }^{2}$ \\ and Shinichi Yonekura ${ }^{1,2,3 *}$ (1) \\ ${ }^{1}$ Graduate School of Medicine, Science and Technology, Institute for Biomedical Sciences, Interdisciplinary Cluster for Cutting Edge Research, \\ Shinshu University, Nagano 399-4598, Japan \\ ${ }^{2}$ Graduate School of Science and Technology, Institute for Biomedical Sciences, Interdisciplinary Cluster for Cutting Edge Research, \\ Shinshu University, Nagano 399-4598, Japan \\ ${ }^{3}$ Department of Biomolecular Innovation, Institute for Biomedical Sciences, Interdisciplinary Cluster for Cutting Edge Research, \\ Shinshu University, Nagano 399-4598, Japan
}

\section{ABSTRACT}

Fatty acids play important roles in the regulation of endoplasmic reticulum (ER) stress-induced apoptosis in different cells. Currently, the effects of fatty acids on bovine mammary epithelial cells (MEC) remain unknown. Our study examined bovine MEC viability and measured unfolded protein response (UPR)-related gene and protein expressions following fatty acid treatments. To evaluate the role of fatty acids, we treated MAC-T cells (a line of MEC) with 100 to $400 \mu M$ of saturated (palmitic and stearic acid) and unsaturated (palmitoleic, oleic, linoleic, and linolenic acid) fatty acids and 1 to $5 \mathrm{~m} M$ of short- and medium-chain fatty acids (acetic, propionic, butyric, and octanoic acid). Thereafter, we determined UPR-related gene expression using quantitative real-time PCR. Palmitic acid stimulated expression of $X B P 1 s, A T F 4, A T F 6 A$, and C/EBP homologous protein $(C H O P)$. Stearic acid increased expression of $X B P 1 s$ and $C H O P$ and decreased expression of ATF4 and ATF6A. Results of Western blot analysis and 3-(4,5-dimethylthiazol-2-yl)-2,5-diphenyltetrazolium bromide (MTT) assay revealed that palmitic and stearic acid reduced MAC-T cell viability and induced extreme ER stress by increasing the protein expression of ER stress markers, such as phospho-PKR-like endoplasmic reticulum kinase, phospho-eIF $2 \alpha$, cleaved CASP-3, and CHOP. Among unsaturated long-chain fatty acids, palmitoleic acid increased expression of $A T F 4$ and $A T F 6 A$. Oleic acid increased expression of $X B P 1 s, A T F 4$, and $A T F 6 A$. Linoleic and linolenic acids increased expression of $X B P 1 s, A T F 4$, and $A T F 6 A$ but decreased expression of $X B P 1 s$ and $A T F 6 A$ at the

Received December 19, 2019.

Accepted April 20, 2020.

*Corresponding author: yonekura@shinshu-u.ac.jp highest dose. Although palmitoleic, oleic, and linoleic acid decreased CHOP expression, only palmitoleic acid increased MAC-T cell viability. Therefore, unsaturated long-chain fatty acids did not induce severe ER stress. Acetic, propionic, and butyric acids decreased expression of $A T F 4, A T F 6 A$, and $C H O P$ and increased $X B$ $P 1 s$ expression. Although only octanoic acid increased $A T F 4$ and ATF6A expressions, it lowered expression of $X B P 1 s$ and $C H O P$. Although fatty acid treatment did not increase the levels of ER stress proteins, butyric and octanoic acids reduced cell viability, possibly because of early differentiation. These results suggest that saturated fatty acids play important roles in MEC viability by inducing severe ER stress compared with unsaturated fatty acids. In addition, acetic and propionic acids (short- and medium-chain fatty acids) reduced ER stress. Therefore, the present study reflects the new insight that serum fatty acid concentration plays an important role in maintaining the lactation physiology of dairy cows.

Key words: mammary epithelial cells, unfolded protein response, endoplasmic reticulum stress, apoptosis

\section{INTRODUCTION}

Bovine mammary glands are exocrine glands that consist of millions of secretory cells, known as mammary epithelial cells (MEC), and are considered the main functional units for milk production. The number of MEC and their secretory activity determine the amount of milk produced during a lactation period (Capuco et al., 2001). Therefore, elucidating the factors that regulate MEC proliferation and cell death is crucial to maintaining optimum milk yield.

Over the last several decades, the development of intense breeding strategies and improvements in dairy cattle nutrition and management have greatly increased milk yields, particularly in the Holstein-Friesian cattle 
breed (Bruckmaier, 2001; Cassell, 2001; Ferland et al., 2018). However, the achievements in this economically favorable trait have led to some negative consequences. For example, during the transition period, at the onset of lactation, milk yield, milk proteins, and fat and lactose synthesis show a rapid increase and are associated with a decreased feed dry matter intake by up to $40 \%$ (Hayirli and Grummer, 2004), which results in a negative energy balance (NEB; Janovick et al., 2011). The NEB is one of the causes of reduced milk yield (Drackley, 1999) and lowered reproductive performance through metabolic diseases, including ketosis, fatty liver, and displaced abomasum (Collard et al., 2000). Extreme NEB at calving can be responsible for retained placenta, mastitis, milk fever, or postpartum uterine infections (Melendez et al., 2009; Leblanc, 2010).

Under NEB conditions, dairy cows use body fat for maintaining energy requirements and produce nonesterified fatty acids, mainly C16:0, C18:0, and cis-9 C18:1 and C14:0, cis-9 C16:1, C17:0, trans-11 C18:1, and minor fatty acids, albeit to a much lesser extent (Bas et al., 1987). The MEC utilize fatty acids as energy substrates as well as for milk lipid synthesis; however, fatty acids exert innumerable effects on various tissues. Several studies have demonstrated that saturated nonesterified fatty acids (palmitic and stearic acids) are proapoptotic, whereas unsaturated fatty acids are antiapoptotic factors in $\beta$-cells (Eitel et al., 2002), coronary artery endothelial cells (Staiger et al., 2006), and human breast cancer cells (Hardy et al., 2000, 2003). In addition, palmitic and stearic acids cause endoplasmic reticulum (ER) stress in various types of nonruminant cells (Maedler et al., 2001; Wei et al., 2006; Sieber et al., 2010; Haywood and Yammani, 2016). However, the detailed molecular mechanisms regarding the effects of long- and short-chain fatty acids on bovine MEC remain unclear.

The ER is the main site of protein, steroid, and cholesterol biosynthesis as well as biosynthesis of other lipids. The normal synthetic capacity of the ER can be disrupted by increased general protein synthesis, nutrient deprivation, calcium homeostatic changes, and post-translational modification failure (Bando et al., 2004; Badr et al., 2007), leading to accumulation of unfolded proteins. During impaired homeostasis, an adaptive network of signaling cascades, known as the unfolded protein response (UPR), is activated by 3 stress-sensor transmembrane proteins: PKR-like endoplasmic reticulum kinase (PERK), inositol requiring enzyme 1 (IRE1), and activating transcription factor 6 (ATF6; Patil and Walter, 2001; Ron, 2002). Under ER stress conditions, the activated PERK inhibits general protein translation and promotes the translation of ATF4 (a transcription factor) via phosphorylation of eukaryotic initiation factor $2 \alpha$ (eIF-2 $\alpha$; Harding et al., 1999, 2000; Chan et al., 2017). In severe or persistent ER stress conditions, ATF 4 increases the transcription of the $\mathrm{C} / \mathrm{EBP}$ homologous protein $(\mathrm{CHOP})$, which acts as a transcription factor and induces cell apoptosis (Zinszner et al., 1998). Activated IRE1 triggers production of the transcription factor spliced $X B P 1(X B P 1 s)$ from unspliced XBP1 (XBP1u) mRNA (Calfon et al., 2002; Yoshida et al., 2003). Depending on the type of ER stress, ATF6a is modified to active ATF6a in the Golgi apparatus and migrates to the nucleus to act as a transcription factor (Ye et al., 2000).

Bovine MEC sense ER stress due to increases in milk synthesis during the lactation period. A recent study suggested that energy supplemented via proteins promoted expression of $X B P 1 s$, activating the IRE1 arm of the UPR in the bovine mammary gland (Nichols et al., 2019). Invernizzi et al. (2012) reported elevated $A T F 4, C H O P$, and PERK expression levels after initiation of lactation, with no changes in XBP1 and $A T F 6$ expression levels. Our previous study has demonstrated that XBP1s, ATF 4, and CHOP expression levels were significantly increased immediately following parturition. Among these, $C H O P$ expression was negatively correlated with initial milk yield in bovine mammary gland tissue (Yonekura et al., 2018), strongly affirming the loss of numerous MEC because of ER stress affecting milk yield. Therefore, the UPR plays a significant role in the survival of MEC. Accordingly, in the present study, we determined whether long- and short-chain fatty acids affect UPR gene expression, and consequently cell viability, in bovine MEC. Thus, we focused on the effects of fatty acids on the mammary gland environment of dairy cows.

\section{MATERIALS AND METHODS}

\section{Reagents}

Dulbecco's modified Eagle medium was purchased from Invitrogen (Carlsbad, CA). Fetal bovine serum (FBS) was purchased from Equitech-Bio Inc. (Kerrville, TX). Penicillin, streptomycin, and gentamicin; bovine hydrocortisone and insulin; sheep pituitary prolactin; sodium stearate; and sodium octanoate were purchased from Sigma-Aldrich (St. Louis, MO). Recombinant bovine growth hormone was purchased from Ray Biotech (Norcross, GA). All other compounds were obtained from Nacalai Tesque (Kyoto, Japan).

\section{Preparation of Fatty Acid Solutions}

Palmitic and stearic acid solutions were prepared as previously described by Qi et al. (2014) with minor 
modifications. The stock solution of LCFA was made by dissolving the required amount of a specific acid in dimethyl sulfoxide warmed at $60^{\circ} \mathrm{C}$ with continuous shaking. Then, various concentrations of the prepared solutions were mixed with $10 \%$ (wt/vol) BSA/ PBS (fatty acid-free) and heated for 10 to $15 \mathrm{~min}$ at $55^{\circ} \mathrm{C}$ with continuous shaking. The resulting solutions were added to the cell culture medium before treatment to obtain the desired final concentrations (100, 200, 300, 400, and $500 \mu M$ ) and $0.1 \%$ BSA. To obtain unsaturated long-chain fatty acid solutions, the optimum amounts of specific fatty acids were dissolved in fatty acid-free $10 \% \mathrm{BSA} / \mathrm{PBS}$ warmed at $37^{\circ} \mathrm{C}$ for 30 min and mixed by vortexing. The optimum amounts of specific short- and medium-chain fatty acids were dissolved in growth medium containing 10\% FBS heated at $37^{\circ} \mathrm{C}$ for 30 min to obtain stock solution, which was further mixed by vortexing. Following sterilization, all the long-chain fatty acid solutions were stored at $-20^{\circ} \mathrm{C}$, except for stearic acid. Steric acid and all of the short- and medium-chain fatty acid solutions were stored at $4^{\circ} \mathrm{C}$ and protected from light until further use.

\section{Cell Culture and Fatty Acid Treatments}

Immortalized bovine MEC (MAC-T cells) were generously provided by Sangun Roh of Tohoku University, Sendai, Japan. Cells were cultured in Dulbecco's modified Eagle medium containing 10\% FBS, $1 \%$ penicillin and streptomycin, $5 \mu \mathrm{g} / \mathrm{mL}$ bovine insulin, and $1 \mu \mathrm{g} /$ $\mathrm{mL}$ hydrocortisone in $35-\mathrm{mm}$ dishes. Hundred-percent confluent cells were treated with saturated and unsaturated long-chain fatty acids $(100,200,300$, and $400 \mu M)$ and short- and medium-chain fatty acids $(1,3$, and 5 $\mathrm{m} M$ ) in growth medium containing $10 \%$ FBS for $12 \mathrm{~h}$. All cultures were maintained at $37^{\circ} \mathrm{C}$ under $5 \% \mathrm{CO}_{2}$.

\section{RNA Extraction and Quantitative Real-Time PCR}

Total RNA was isolated from MAC-T cells using TRIzol (Invitrogen) according to the manufacturer's protocol. Reverse transcription was performed using a quantitative real-time PCR Master Mix with gDNA Remover (Toyobo, Osaka, Japan) according to the manufacturer's instructions. Quantitative realtime PCR was performed using the SYBR Premix Ex TaqTM 11 (TaKaRa Biotechnology, Kusatsu, Japan). Gene expression of XBP1s, ATF4, ATF6A, and $C H O P$ were assessed. Relative transcript expression was calculated via the $2^{-\Delta \Delta \mathrm{Ct}}$ method and represented as values relative to control. The GAPDH and VPS4A genes were used as references. Primer sequences were used according to Yonekura et al. (2018). The primer sequence of GAPDH was AATGGAAAGGCCATCA (forward) and GTGGTTCACGCCCATC (reverse). The primer sequence of VPS4A was CAAAGCCAAGGAGAGCATTC (forward) and ATGTTGGGCTTCTCCATCAC (reverse). Sensitivity of the reaction and amplification of contaminating products, such as extension of self-annealed primers, were evaluated by amplifying serial cDNA dilutions. Data analysis was performed according to the manufacturer's instructions.

\section{Cell Viability Test}

We seeded MAC-T cells seeded at a density of $2 \times$ $10^{3}$ cells/well in 96-well plates and incubated them in culture medium. The cells were treated with 200 and $400 \mu M$ saturated and unsaturated fatty acids and 1,3 , and $5 \mathrm{~m} M$ short- and medium-chain fatty acids. After $48 \mathrm{~h}$, cell viability was measured using the 3-(4,5-dimethylthiazol-2-yl)-2,5-diphenyltetrazolium bromide (MTT) Cell Viability Assay Kit (Biotium, Fremont, CA) according to the manufacturer's protocol. Briefly, $10 \mu \mathrm{L}$ of the MTT solution was added to $100 \mu \mathrm{L}$ of culture medium. After $4 \mathrm{~h}$ of incubation at $37^{\circ} \mathrm{C}, 200 \mu \mathrm{L}$ of dimethylsulfoxide was added to each well. The absorbance was measured using a multimode microplate reader (iMark microplate reader, Bio-Rad Laboratories, Hercules, CA) at $570 \mathrm{~nm}$ and a reference wavelength of $630 \mathrm{~nm}$.

\section{Western Blot Analysis}

Cells were washed twice, following which they were lysed with radioimmunoprecipitation assay lysis buffer (50 $\mathrm{m} M$ Tris- $\mathrm{HCl} \mathrm{pH} 7.4,150 \mathrm{~m} M \mathrm{NaCl}, 0.05 \%$ SDS, $0.2 \%$ sodium deoxycholate, $1 \mathrm{mM}$ EDTA, and $1 \%$ NP40) containing a protease inhibitor cocktail (Nakalai Tesque, Kyoto, Japan), and the lysates were incubated on ice for $30 \mathrm{~min}$. Following centrifugation (10 min at $20,000 \times g)$, the protein concentrations in the lysates were determined using a Bio-Rad protein assay kit. The cell extracts $(60 \mu \mathrm{g})$ were subjected to SDS-PAGE on a 4 to $20 \%$ polyacrylamide gel, following which they were transferred to a polyvinylidene difluoride membrane. The membrane was incubated for $1 \mathrm{~h}$ in $1 \% \mathrm{PBT}$ (1\% Tween 20 in PBS) and $0.01 \%$ Tween 20 solution containing $4 \%$ skim milk powder (blocking buffer) and probed using antibodies against phosphorylated PERK (Santa Cruz Biotechnology, Santa Cruz, CA), total PERK (Santa Cruz Biotechnology), phosphorylated eIF $2 \alpha$ (Invitrogen), total eIF2 $\alpha$ (Invitrogen), CHOP (Life Span Bioscience Inc., Seattle, WA), cleaved CASP-3 (Cell Signaling Technology, Danvers, MA), and $\alpha$-tubulin (MBL Co., Nagoya, Japan) diluted in block- 
ing buffer at room temperature. The membranes were then incubated with horseradish peroxidase-conjugated secondary antibodies. After incubation with enhanced chemiluminescence, anti-rabbit IgG (GE Healthcare, Pittsburgh, PA)-labeled proteins were visualized using an Enhanced Chemiluminescent Prime Western Blotting Detection Reagent kit (GE Healthcare), and images were obtained using an Image Quant LAS 500 (GE Healthcare).

\section{Statistical Analysis}

Values were expressed as the mean \pm standard error of the mean from a typical experiment that was run in triplicates dishes. Statistical difference was determined using one-way ANOVA followed by Dunnett's test. The test was considered significant at $P<0.05$.

\section{RESULTS}

\section{Effect of Saturated Long-Chain Fatty Acids (Palmitic and Stearic Acid) on MAC-T Cells}

The proapoptotic factor $C H O P$ was significantly upregulated by 200, 300, and $400 \mu M$ palmitic and stearic acids. Both palmitic and stearic acids significantly increased $X B P 1 s$ expression. Gene expressions of $A T F 4$ and ATF6A were enhanced by palmitic acid but downregulated by stearic acid (Figure 1A).

To confirm the detrimental effect of palmitic and stearic acids on bovine MEC, we performed Western blot analysis to measure phospho-PERK, phosphoeIF $2 \alpha$, CHOP, and cleaved CASP-3 protein expressions. Palmitic and stearic acid treatments increased expression of phospho-PERK, phospho-eIF2 $\alpha$ CHOP, and cleaved CASP-3 protein (Figure 1B).

Because both palmitic and stearic acids upregulated the expression of proapoptotic marker CHOP and cleaved caspase 3, we examined whether saturated long-chain fatty acids affected MAC-T cell viability using the MTT assay. Compared with the control, both palmitic and stearic acids at 200 and $400 \mu M$ significantly reduced bovine MEC viability (Figure 1C).

\section{Effect of Unsaturated Long-Chain Fatty Acid (Palmitoleic, Oleic, Linoleic, and Linolenic Acids) Treatment in MAC-T Cells}

We hypothesized that ER stress-induced UPRrelated gene expression in bovine MEC will be affected by treatment with unsaturated long-chain fatty acids (100 to $400 \mu M)$. With the exception of linolenic acid, the highest dose of palmitoleic, oleic, and linoleic acids significantly reduced $C H O P$ gene expression compared with the control (Figure 2A). Expression of XBP1s mRNA was increased by oleic, linoleic, and linolenic acids at different concentrations. However, only the highest doses of linoleic and linolenic acids decreased $X B P 1 s$ expression. Expression of ATF 4 was upregulated by all of the unsaturated fatty acids. Expression of ATF6A was also increased by all of the unsaturated fatty acids, except for the highest doses of linoleic and linolenic acids, compared with the controls.

Because unsaturated long-chain fatty acids did not enhance $C H O P$ gene expression, we hypothesized that those fatty acids would not negatively affect bovine MEC. Thereafter, we examined phospho-PERK, phospho-eIF2 $\alpha$, CHOP, and cleaved CASP-3 protein expressions using Western blot analysis. The results indicated that unsaturated long-chain fatty acids did not increase expression of phospho-PERK, phospho-eIF $2 \alpha$, cleaved CASP-3, or CHOP proteins compared with the palmitic acid-treated group (Figure 2B).

Further, we examined MAC-T cell viability using the MTT assay. None of the unsaturated fatty acids affected bovine MEC viability, and $400 \mu M$ palmitoleic acid significantly increased the proliferation of MEC (Figure 2C).

\section{Effect of Short- and Medium-Chain Fatty Acids (Acetic, Propionic, Butyric, and Octanoic Acids) in MAC-T Cells}

Quantitative real-time PCR analysis showed that all short- and medium-chain fatty acids significantly downregulated $C H O P$ gene expression compared with the controls. Acetic, propionic, and butyric acids enhanced XBP1s expression but reduced ATF4 and AT$F 6 A$ expression. Only $5 \mathrm{~m} M$ of octanoic acid increased $A T F 4$ and ATF $6 A$ expression via the downregulation of $X B P 1 s$ (Figure $3 \mathrm{~A}$ ).

Most short- and medium-chain fatty acids downregulated $A T F 4, A T F 6 A$, and $C H O P$ expression. Therefore, we considered that short- and medium-chain fatty acids might reduce ER stress. Western blot results showed that none of the short- and medium-chain fatty acids increased p-PERK, p-eIF2 $\alpha$, or CHOP protein levels compared with the palmitic acid-treated cells. Moreover, cleaved CASP-3 protein was not visible via Western blot for any short- or medium-chain fatty acidtreated cells (Figure 3B).

To confirm the ER stress-reducing characteristics of short- and medium-chain fatty acids, we performed the MTT assay to analyze cell viability. Only 3 and $5 \mathrm{mM}$ butyric and $5 \mathrm{~m} M$ octanoic acid significantly decreased the cell viability (Figure $3 \mathrm{C}$ ). 
A

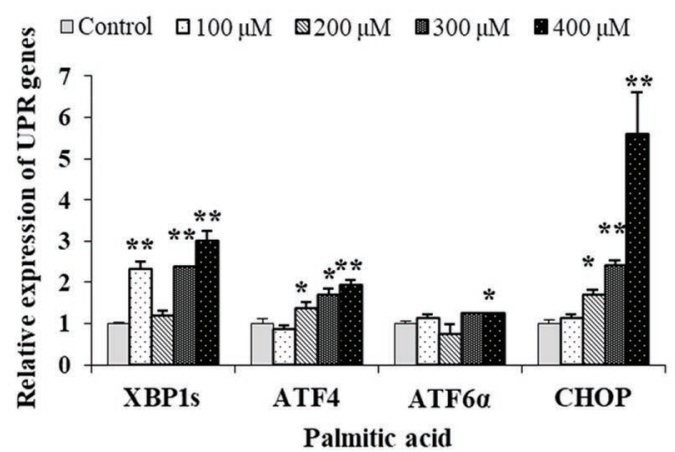

Palmitic acid

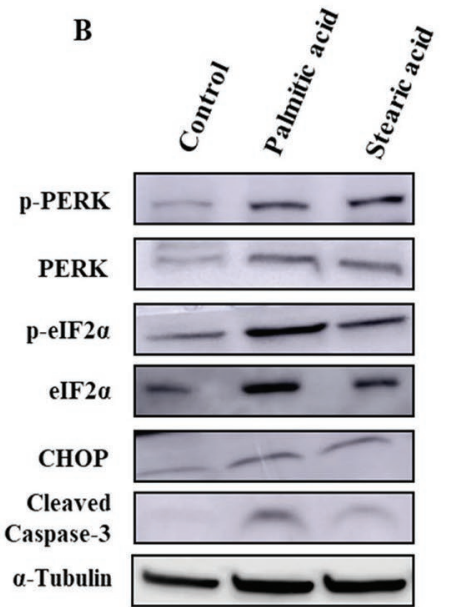

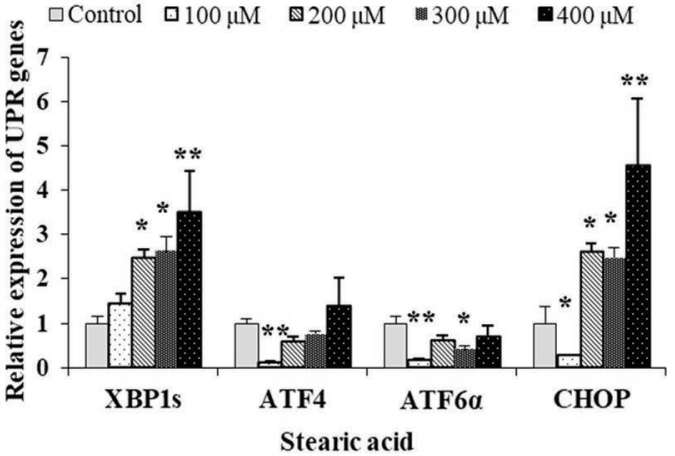

C

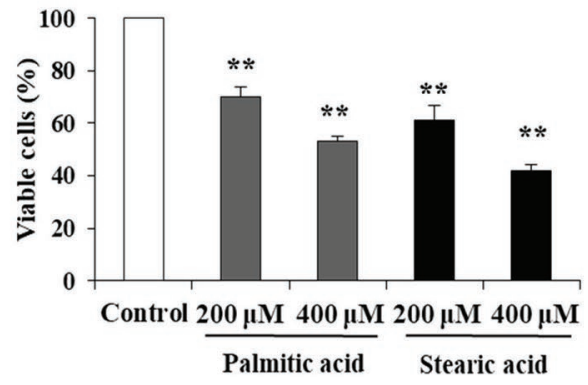

Figure 1. Effects of saturated long-chain fatty acids on endoplasmic reticulum stress-induced unfolded protein response (UPR)-related gene and protein expression and bovine mammary epithelial MAC-T cell viability. (A) Expression pattern of UPR-related genes in control and 100, 200, 300, and $400 \mu M$ palmitic and stearic acid-treated MAC-T cells for $12 \mathrm{~h}$, determined using real-time PCR of XBP1s, ATF/, ATF6A, and CHOP mRNA. Relative transcript expression was calculated by the $2^{-\Delta \Delta \mathrm{Ct}}$ method and presented as values relative to control. (B) MAC-T cells were stimulated with $400 \mu M$ palmitic acid and stearic acids for $12 \mathrm{~h}$, and phosphorylated (P) PERK, PERK, P-eIF2 $\alpha$, eIF2 $\alpha$, CHOP, cleaved CASP-3, and $\alpha$-tubulin (internal control) protein levels were detected using the Western blot method. Representative images from at least 3 independent experiments with at least 4 replicates in each experiment are shown. (C) Cell viability was measured using 3-(4,5-dimethylthiazol2-yl)-2,5-diphenyltetrazolium bromide assay. Cells that were 90 to $100 \%$ confluent were treated with 200 and $400 \mu M$ palmitic and stearic acids for $48 \mathrm{~h}$. Absorbance was measured at 570 and $630 \mathrm{~nm}$ using a multimode microplate reader to calculate survival rates (\%) of cells. Data are presented as mean \pm SEM for 3 independent experiments. ${ }^{*}$ indicates $P<0.05$ and $* *$ indicates $P<0.01$ compared with control, determined using 1-way ANOVA followed by Dunnett's test.

\section{DISCUSSION}

Excessive accumulation of free fatty acids in any non-adipose tissue may cause cells to dysfunction and undergo apoptosis. The cell signaling pathways and molecular mechanisms that play a role in cell death induced by the accumulation of fatty acids have not yet been completely elucidated. To the best of our knowledge, this is the first study identifying a relationship between fatty acid treatment and ER stress-induced UPR-related gene expression in bovine MEC.

The present study demonstrated that palmitic and stearic acids induced CHOP overexpression at both the
mRNA and protein levels in dose-dependent fashion (Figure $1 \mathrm{~A}$ and B). The $100 \mu M$ solutions of palmitic and stearic acids did not upregulate the $C H O P$ expression in bovine MEC. The concentration of nonesterified fatty acids mainly changed according to the degree of lipomobilization during the transition period. The saturated and unsaturated long-chain fatty acid treatment (100 to $400 \mu M$ ) used in this study may be higher compared with the in vivo concentration of bovine serum free fatty acid; however, knowledge from the in vitro experiment helped us fix the fatty acid treatment dosage that was applied to MAC-T cells. Qi et al., (2014) treated bovine MEC with 0 to $600 \mu M$ palmitic 
A

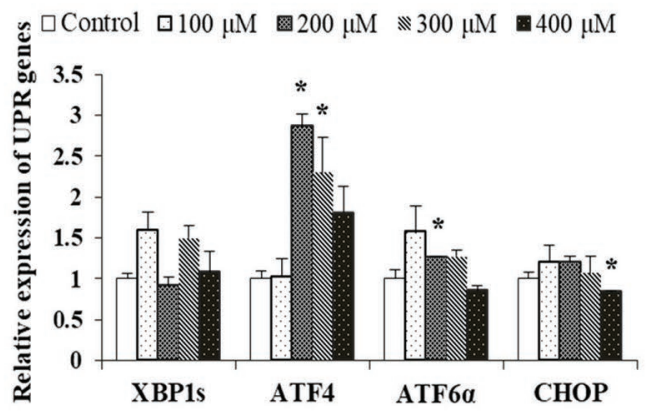

Palmitoleic acid

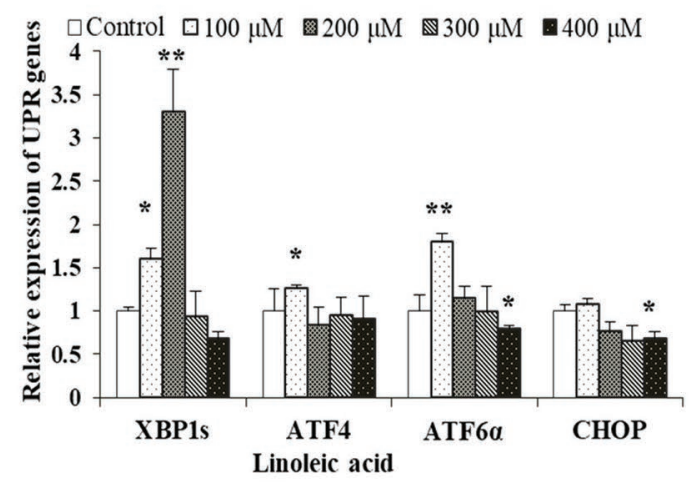

B

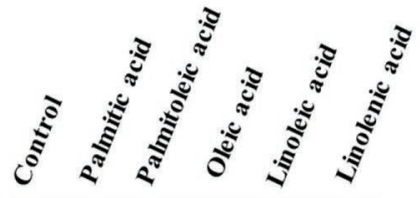

P-PERK

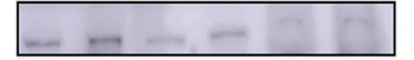

PERK

P-eIF2 $\alpha$
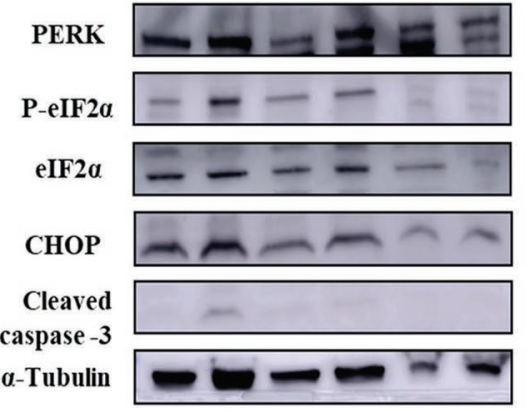
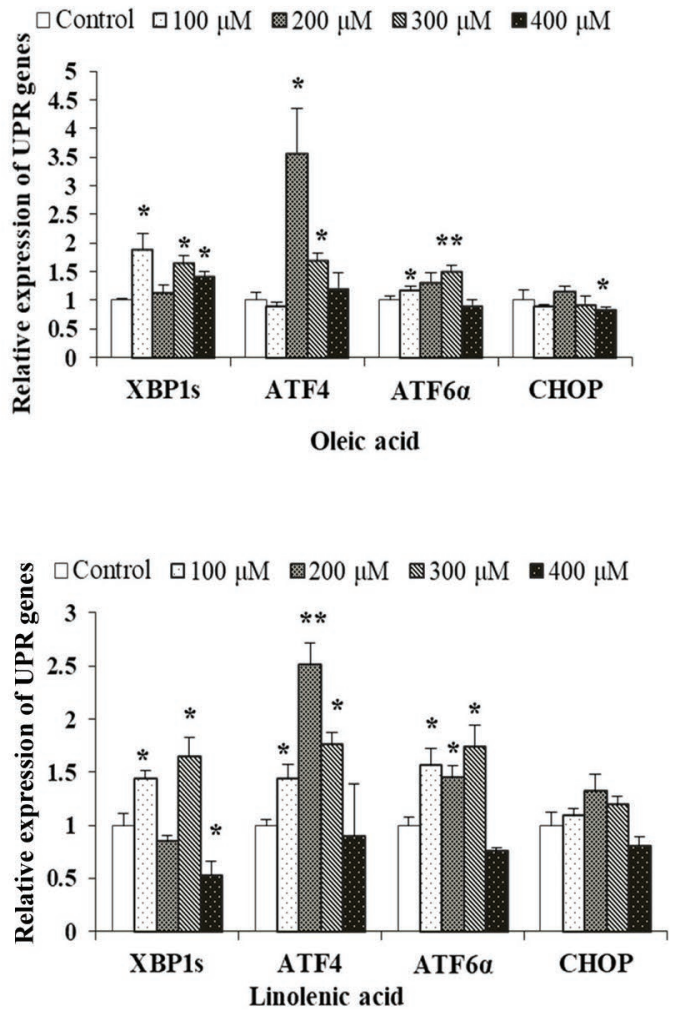

C

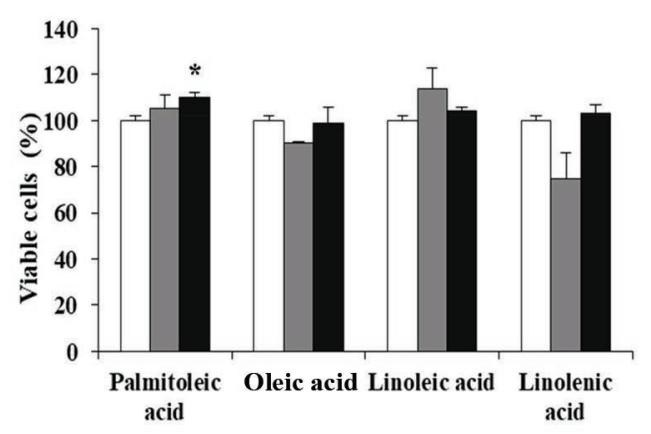

Figure 2. Effects of unsaturated long-chain fatty acids on endoplasmic reticulum stress-induced unfolded protein response (UPR)-related gene and protein expression and bovine mammary epithelial MAC-T cell viability. (A) UPR-related gene expression in control and 100, 200, 300 and $400 \mu \mathrm{M}$ palmitoleic, oleic, linoleic, and linolenic acid-treated MAC-T cells for $12 \mathrm{~h}$, assessed using real-time PCR of XBP1s, ATF4, ATF6A, and $C H O P$ mRNA. Relative transcript expression was calculated by the $2^{-\Delta \Delta \mathrm{Ct}}$ method and presented as values relative to control. (B) MAC-T cells were treated with $400 \mu \mathrm{M}$ palmitic acid (as a positive control), palmitoleic acid, oleic acid, linoleic acid, and linolenic acid for $12 \mathrm{~h}$, and the phosphorylated (P) PERK, PERK, P-eIF2 $\alpha$, eIF2 $\alpha$, cleaved CASP-3, CHOP, and $\alpha$-tubulin (internal control) protein levels were detected using Western blotting. Representative images from at least 3 independent experiments with at least 4 replicates in each experiment are shown. (C) Cell viability was measured using 3-(4,5-dimethylthiazol-2-yl)-2,5-diphenyltetrazolium bromide assay. Cells that were 90 to $100 \%$ confluent were treated with 200 and $400 \mu \mathrm{M}$ palmitoleic, oleic, linoleic, and linolenic acids for $48 \mathrm{~h}$. Absorbance was measured at 570 and $630 \mathrm{~nm}$ using a multimode microplate reader to calculate survival rates (\%) of cells. Data are presented as mean \pm SEM for 3 independent experiments. ${ }^{*}$ indicates $P<0.05$ and ${ }^{* *}$ indicates $P<0.01$ compared with control, determined using 1-way ANOVA followed by Dunnett's test. 
A
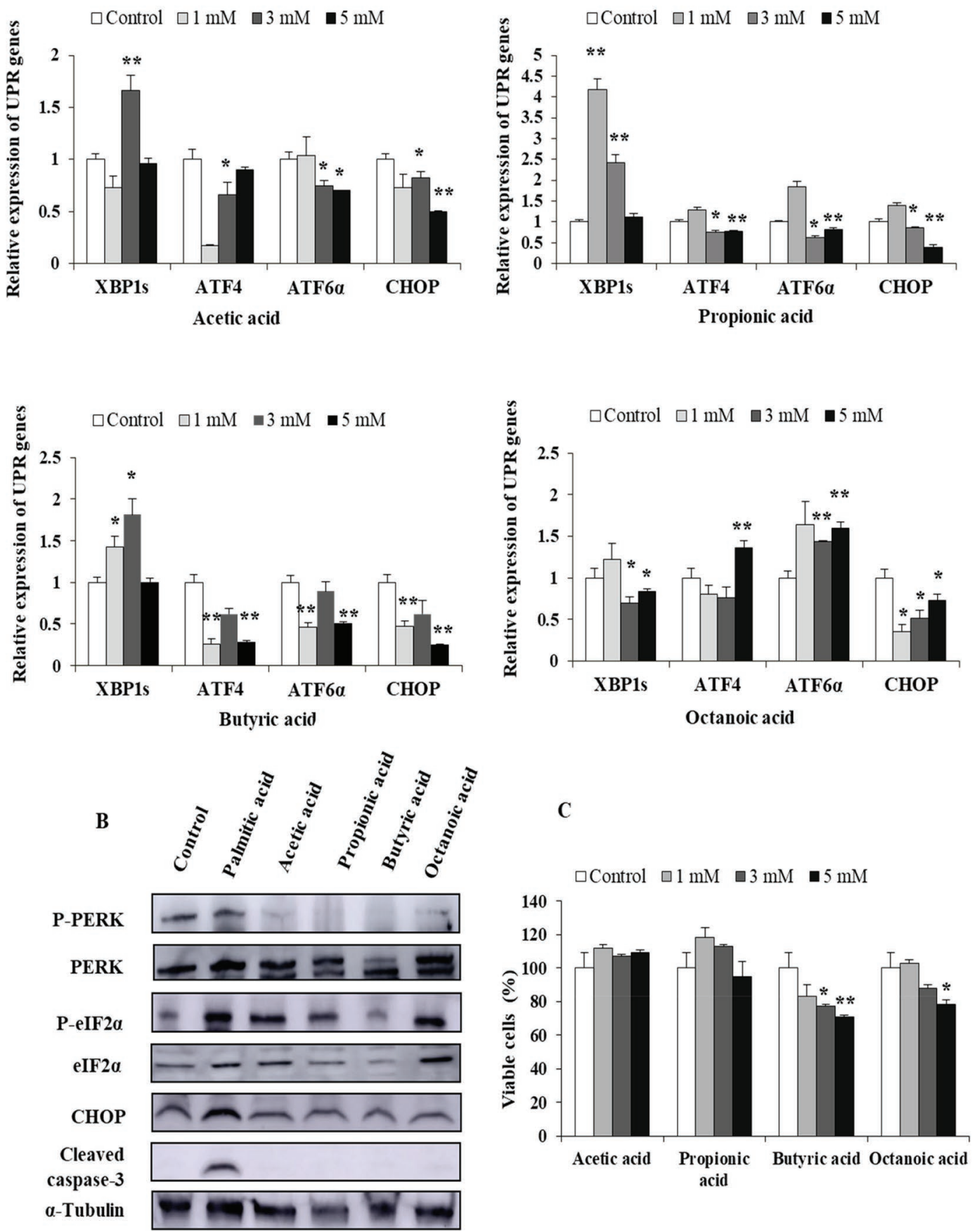

Figure 3. Effect of short- and medium-chain fatty acids on endoplasmic reticulum stress-induced unfolded protein response (UPR)-related gene and protein expression and bovine mammary epithelial MAC-T cell viability. (A) Expression pattern of UPR-related genes in control, 1, 3 , and $5 \mathrm{~m} M$ acetic, propionic, butyric, and octanoic acid-treated MAC-T cells for $12 \mathrm{~h}$, determined using real-time PCR of XBP1s, ATF4, $A T F 6 A$, and $C H O P$ mRNA. (B) Relative transcript expression was calculated by the $2^{-\triangle \Delta C t}$ method and represented as values relative to control. MAC-T cells were supplemented with $400 \mu M$ palmitic acid (as a positive control group) or $5 \mathrm{~m} M$ acetic, propionic, butyric, or octanoic acid for $12 \mathrm{~h}$, and the phosphorylated (P) PERK, PERK, P-eIF2 $\alpha$, eIF2 $\alpha$, cleaved CASP-3, CHOP and $\alpha$-tubulin (internal control) protein levels were detected using Western blotting. Representative images from 3 independent experiments with at least 4 replicates in each experiment are shown. (C) Cell viability was measured using 3-(4,5-dimethylthiazol-2-yl)-2,5-diphenyltetrazolium bromide assay. Cells that were 90 to $100 \%$ confluent were treated with 1,3 , and $5 \mathrm{mM}$ acetic, propionic, butyric, and octanoic acid for $48 \mathrm{~h}$. Absorbance was measured at 570 and 630 $\mathrm{nm}$ using a multimode microplate reader to calculate survival rates (\%) of cells. Data are presented as mean \pm SEM for 3 independent experiments. ${ }^{*}$ indicates $P<0.05$ and ${ }^{* *}$ indicates $P<0.01$ compared with the control, determined using 1-way ANOVA followed by Dunnett's test 
and stearic acids, to discover the effects of saturated fatty acids on gene expression related to milk fat and protein biosynthesis. Yonezawa et al. (2004a, 2008) used 50 to $400 \mu M$ saturated long-chain fatty acids for measuring cytosolic triacylglycerol accumulation, lipid droplet formation, and uncoupling protein-2 expression in bovine MEC. Moreover, Vargas-Bello-Pérez et al. (2019) treated MAC-T cells with 100 to $400 \mu M$ saturated long-chain fatty acids to determine cytosolic triacylglycerol content. Furthermore, we followed previous studies (Yonezawa et al., 2004b; Sun et al., 2016) for fixing the doses of short- and medium-chain fatty acid treatments.

As observed, ER membrane integrity was impaired by the permeabilization and leakage of ER contents into the cytosol and also by ER stress induced by palmitic acid treatment (Hitomi et al., 2004; Kanekura et al., 2015). When cells were treated with palmitic acid, the saturation of the ER membrane resident lipid species was increased, and thus the membrane became less flexible (Weijers, 2012; Kanekura et al., 2015). Kanekura et. al. (2015) also found that in palmitic acid-treated ER membrane disrupted cells, the ER stress-induced UPR-related gene CHOP was upregulated, which was consistent with the results of the 200 to $400 \mu M$ saturated long-chain fatty acid treatment in the present study. Therefore, palmitic and stearic acids are ligands for disrupting ER membrane homeostasis and inducing ER stress. However, in fatty acid treatment of MAC-T cells where growth medium containing FBS was used, a percentage of fatty acids was detected, although we also used the same FBS-containing growth medium for the control cells. Therefore, we thought that the cells of both control and fatty acid-treated groups may have received an indistinguishable amount of fatty acids from FBS.

Typically, CHOP is ubiquitously expressed at extremely low levels in non-stress conditions; however, in most cells, CHOP expression increases when the cells are subjected to severe stress (Chikka et al., 2013). Cell death mediated by ER stress requires CHOP overexpression (Matsumoto et al., 1996; Maytin et al., 2001; Oyadomari et al., 2001), which was observed following high doses of saturated long-chain fatty acid treatments in MAC-T cells. The UPR is sensed by 3 arms: PERK, IRE1, and ATF6. Among these proteins, the PERK/ eIF2 $\alpha$-signaling pathway is essential for induction of the proapoptotic transcriptional factor $\mathrm{CHOP}$ under ER stress conditions and is dominant over the ATF6 and IRE1/XBP-1 signaling pathways (Harding et al., 2000; Scheuner et al., 2001). Both palmitic and stearic acids significantly increased expression of phospho-PERK and phospho-eIF $2 \alpha$ compared with control cells (Figure
1B), leading to the activation of the PERK arm of the UPR under ER stress conditions in MAC-T cells. Wei et al. (2006) postulated that palmitic and stearic acids caused rat liver cell death by upregulating expression of the CHOP gene. Consistent with our results, that study found that palmitic and stearic acids disrupted ER homeostasis, increased phosphorylation of eIF2 $\alpha$ and ATF 4 mRNA, and induced $C H O P$ expression.

Both palmitic and stearic acid-treated cells showed higher cleaved CASP-3 protein expression compared with control cells (Figure 1C). CASP-3 is a major executioner caspase that undergoes cleavage and is activated for the degradation of multiple cellular proteins, and it is responsible for morphological changes and DNA fragmentation in cells during apoptosis (McIlwain et al., 2013). Previous studies have demonstrated saturated fatty acid-induced CASP-3-dependent apoptosis in various cell types (Hardy et al., 2003; Wang et al., 2006; Wei et al., 2006). Considering the findings of Hardy et al. (2003), Wang et al. (2006), and Wei et al. (2006), palmitic and stearic acids induced apoptosis of bovine MEC by increasing the expression of cleaved CASP-3. Therefore, for the first time, our study suggested that bovine MEC experienced extreme ER stress due to treatment with 200 to $400 \mu M$ palmitic and stearic acids. This study indicated that excessive saturated long-chain fatty acids in the mammary glands of dairy cows may be harmful, as it negatively affects optimum milk production.

Palmitoleic, oleic, linoleic, and linolenic acids reduced expression of the CHOP gene as well as phospho-PERK, phospho-eIF $2 \alpha$, and CHOP protein expression in bovine MEC (Figure $2 \mathrm{~A}$ and B). Previous studies have shown that palmitoleic, oleic, and linoleic acid-treated cells did not upregulate CHOP expression. Further, those fatty acids rescued the palmitic acid-induced CHOP expression under coculture conditions (Listenberger et al., 2003; Wei et al., 2006; Sieber et al., 2010). In addition to decreasing the capacity of CHOP, palmitoleic and $\alpha$-linolenic acids exhibited the ability to reduce ER stress and facilitated downstream signaling of phosphoeIF $2 \alpha$ induced by either palmitic acid, salubrinal (phosphatase inhibitor), or tunicamycin (noble ER stress inducer) in the rat renal cell line NRK-52E (Diakogiannaki et al., 2008; Katsoulieris et al., 2009). Therefore, the cytoprotective effect of unsaturated long-chain fatty acids provides mechanistic support for the reduction of ER stress-associated markers, such as phospho-PERK, phospho-eIF2 $\alpha$, and CHOP, when MAC-T cells were cultured with palmitoleic, oleic, linoleic, and linolenic acids. Finally, the present study concluded that unsaturated fatty acids did not cause severe ER stress in bovine MEC, considering that the principal arm of 
the UPR, involving PERK, was not upregulated following unsaturated fatty acid treatment. Moreover, the transcription factor CHOP may interact with $A T F 4$ to bind the promoter regions of genes encoding protein synthesis, thereby enhancing ER stress-induced cell death in wild-type mouse embryo fibroblasts (Han et al., 2013). We speculate that in the unsaturated fatty acid treatment, the upregulated $A T F 4$ mRNA could not become a dimer with a low amount of $C H O P$. Unlike saturated fatty acids, unsaturated fatty acids did not affect the cell viability of bovine MEC, possibly because of the reduced expression of the CHOP gene and ER stress proteins in the present study. Previous studies have observed that palmitoleic and oleic acids did not negatively affect cardiac myocytes (de Vries et al., 1997; Van Bilsen et al., 1997; Welters et al., 2004); this finding is similar to our findings that oleic, linoleic, and linolenic acids did not affect bovine MEC viability. Furthermore, palmitoleic acid treatment increased bovine MEC viability (Figure 2C). This finding is consistent with the explanation provided by Maedler et al. (2001), who stated that palmitoleic acid treatment increased $\beta$-cell viability by providing more energy at a normoglycemic glucose concentration. Finally, the present study primarily concluded that high doses of unsaturated fatty acids induce moderate ER stress and partly contribute to the cytoprotective effect in bovine MEC. Therefore, unsaturated fatty acids, especially palmitoleic acid, have potential to maintain bovine udder physiology through cytoprotection.

This is the first study to introduce ER stress-related molecular mechanisms of short- and medium-chain fatty acid treatment to bovine MEC. Acetic, propionic, and butyric acids accounts for 45 to $70 \%, 15$ to $40 \%$, and 5 to $20 \%$, respectively, of 60 to $160 \mathrm{~m} M$ total short-chain fatty acids produced in the rumen and the attached reticulum (Bergman, 1990; Aschenbach et al., 2009). These 3 short-chain fatty acids are quantitatively the most important for providing $70 \%$ of the energy required by ruminant animals (Kristensen et al., 1998). Our study showed that all short- and mediumchain fatty acids reduced the proapoptotic marker CHOP expression (Figure 3A). Reductions of the ER stress-associated proteins phospho-PERK, phosphoeIF $2 \alpha$, and CHOP were observed following by acetic, propionic, butyric, and octanoic acid treatment in MAC-T cells (Figure 3B). Furthermore, expression of the cleaved CASP-3 protein was completely absent in these short- and medium-chain fatty acid-treated cells. Diao et al. (2019) identified antiapoptotic properties of acetic, propionic, butyric, and octanoic acids in the intestinal cells of weaned piglets. That study reported that the gastric infusion of the earlier-mentioned fatty acids decreased the percentage of apoptotic cells via reduction of gene and protein abundances of CASP-3; this finding is strongly consistent with our result. In accordance with our results, another study found that feeding lactating goats with sodium butyrate reduces high-concentrate diet-induced apoptosis via reduction of the CASP-3 protein in mammary cells (Chang et al., 2018). Therefore, our study demonstrated that acetic, propionic, butyric, and octanoic acids may provide beneficial effects by reducing ER stress proteins.

Although all short- and medium-chain fatty acids significantly downregulated $\mathrm{CHOP}$ without increasing cleaved CASP-3 protein expression, only butyric and octanoic acids affected bovine MEC viability (Figure $3 \mathrm{C})$. Previous studies have shown that acetic and propionic acid did not affect cell viability (Yonezawa et al., 2009; Wei et al., 2017). We observed that acetic and propionic acids did not reduce bovine MEC viability. The antiproliferative effect of butyric acid for bovine MEC, previously established by Yonezawa et al. (2009), was also demonstrated by the present study. Furthermore, the proliferation of HT29 and DLD-1 cells was inhibited by butyric acid via the inhibition of the expression of genes encoding proteins involved in DNA replication, cell cycle, and cell proliferation (Gamet et al., 1992; Ohara and Mori, 2019) and those that induced differentiation (Toscani et al., 1988). AlvaMurillo et al. (2013) observed that sodium octanoate did not reduce bovine MEC viability. By contrast, only the highest dose of octanoic acid affected bovine MEC viability in our study. The decreased viability observed with butyric and octanoic acids in the present study can be attributed to early differentiation. However, the present study suggests that without affecting cell viability, the reduction of ER stress proteins by shortand medium-chain fatty acids, particularly acetic and propionic acids, renders them a favorable option for ameliorating ER stress in bovine MEC. Therefore, of the short- and medium-chain fatty acids, at least acetic and propionic acids are favorable for conserving MEC for dairy cows to maintain optimal milk production

\section{CONCLUSIONS}

The role of fatty acids in inducing ER stress in bovine MEC has remained completely unknown. Our findings uncover the antagonistic effects of saturated and unsaturated and short- and medium-chain fatty acids on the UPR, ER stress, and bovine MEC viability. Increased amounts of saturated fatty acids are detrimental in regulating bovine MEC cell death via ER stress-induced $C H O P$ gene expression. Because $C H O P$ was negatively correlated with milk production (Yonekura et al., 2018), 
it has been postulated that saturated fatty acids might reduce milk production during the transition period via lowering the number of bovine MEC. Unsaturated fatty acids do not induce severe ER stress in bovine MEC. On the other hand, short- and medium-chain fatty acids, particularly acetic and propionic acids, reduce ER stress via downregulation of UPR genes. Therefore, the present study reflects the new insight that serum fatty acid concentration plays an important role in maintaining the lactation physiology of dairy cows.

\section{ACKNOWLEDGMENTS}

This work was supported in part by Grants-in-Aid from the Morinaga Foundation for Health and Nutrition (Tokyo, Japan). We thank Sangun Roh (Tohoku University, Japan) for providing the MAC-T cells. The authors state that they have no conflicts of interest.

\section{REFERENCES}

Alva-Murillo, N., A. Ochoa-Zarzosa, and J. E. López-Meza. 2013. Effects of sodium octanoate on innate immune response of mammary epithelial cells during Staphylococcus aureus internalization. BioMed. Res. Int. 2013:927643.

Aschenbach, J. R., S. Bilk, G. Tadesse, F. Stumpff, and G. Gäbel. 2009. Bicarbonate-dependent and bicarbonate-independent mechanisms contribute to nondiffusive uptake of acetate in the ruminal epithelium of sheep. Am. J. Physiol. Gastrointest. Liver Physiol. 296:G1098-G1107. https://doi.org/10.1152/ajpgi.90442.2008.

Badr, C. E., J. W. Hewett, X. O. Breakefield, and B. A. Tannous. 2007. A highly sensitive assay for monitoring the secretory pathway and ER stress. PLoS One 2:e571. https://doi.org/10.1371/ journal.pone.0000571.

Bando, Y., Y. Tsukamoto, T. Katayama, K. Ozawa, Y. Kitao, O. Hori, D. M. Stern, A. Yamauchi, and S. Ogawa. 2004. ORP150/ HSP12A protects renal tubular epithelium from ischemia-induced cell death. FASEB J. 18:1401-1403. https://doi.org/10.1096/fj.03 -1161 fje.

Bas, P., Y. Chilliard, P. Morand-Fehr, A. Rouzeau, and N. Mandran. 1987. Composition des principaux tissus adipeux de la chèvre Alpine en fin de lactation [Composition of principal adipose tissues of Alpine goats in late lactation]. Ann. Zootech. 36:361-374. https: //doi.org/10.1051/animres:19870402.

Bergman, E. N. 1990. Energy contributions of volatile fatty acids from the gastrointestinal tract in various species. Physiol. Rev. 70:567590. https://doi.org/10.1152/physrev.1990.70.2.567.

Bruckmaier, M. R. 2001. Milk ejection during machine milking in dairy cows. Livest. Prod. Sci. 70:121-124. https://doi.org/10 .1016/S0301-6226(01)00204-4.

Calfon, M., H. Zeng, F. Urano, J. H. Till, S. R. Hubbard, H. P. Harding, S. G. Clark, and D. Ron. 2002. IRE1 couples endoplasmic reticulum load to secretory capacity by processing the $X B P-1$ mRNA. Nature 415:92-96. https://doi.org/10.1038/415092a.

Capuco, A. V., D. L. Wood, R. Baldwin, K. Mcleod, and M. J. Paape. 2001. Mammary cell number, proliferation, and apoptosis during a bovine lactation: Relation to milk production and effect of bST1. J. Dairy Sci. 84:2177-2187. https://doi.org/10.3168/jds.S0022 -0302(01)74664-4.

Cassell, B.G. 2001. Optimal genetic improvement for the high-producing cow. J. Dairy Sci. 84(E. Suppl.):E144-E150.

Chan, S. M. H., X. Zhao, A. Elfowiris, C. Ratnam, and T. P. Herbert. 2017. The role of de novo protein synthesis and SIRT1 in ER stress-induced Atf4 and Chop mRNA expression in mamma- lian cells. Biochimie 138:156-167. https://doi.org/10.1016/j.biochi 2017.04.018.

Chang, G., J. Yan, N. Ma, X. Liu, H. Dai, M. S. Bilal, and X. Shen. 2018. Dietary sodium butyrate supplementation reduces highconcentrate diet feeding-induced apoptosis in mammary cells in dairy goats. J. Agric. Food Chem. 66:2101-2107. https://doi.org/ 10.1021/acs.jafc. 7 b05882.

Chikka, M. R., D. D. McCabe, H. M. Tyra, and D. T. Rutkowski. 2013. C/EBP homologous protein (CHOP) contributes to suppression of metabolic genes during endoplasmic reticulum stress in the liver. J. Biol. Chem. 288:4405-4415. https://doi.org/10.1074/jbc .M112.432344.

Collard, B. L., P. J. Boettcher, J. C. M. Dekkers, D. Petitclerc, and L. R. Schaeffer. 2000. Relationships between energy balance and health traits of dairy cattle in early lactation. J. Dairy Sci. 83:2683-2690. https://doi.org/10.3168/jds.S0022-0302(00)75162 $-9$.

de Vries, E. J., M. M. Vork, H. M. T. Roemen, F. de J. Yvonne, J. P. M. Cleutjens, G. J. van der Vusse, and M. van Bilsen. 1997. Saturated but not mono-unsaturated fatty acids induce apoptotic cell death in neonatal rat ventricular myocytes. J. Lipid Res. 38:1384-1394.

Diakogiannaki, E., H. J. Welters, and N. G. Morgan. 2008. Differential regulation of the endoplasmic reticulum stress response in pancreatic beta-cells exposed to long-chain saturated and monounsaturated fatty acids. J. Endocrinol. 197:553-563. https://doi.org/10 .1677/JOE-08-0041.

Diao, H., A. R. Jiao, B. Yu, X. B. Mao, and D. W. Chen. 2019. Gastric infusion of short-chain fatty acids can improve intestinal barrier function in weaned piglets. Genes Nutr. 14:4. https://doi.org/10 $.1186 / \mathrm{s} 12263-019-0626-\mathrm{x}$.

Drackley, J. K. 1999. Biology of dairy cows during the transition period: The final frontier? J. Dairy Sci. 82:2259-2273. https://doi .org/10.3168/jds.S0022-0302(99)75474-3.

Eitel, K., H. Staiger, M. D. Brendel, D. Brandhorst, R. G. Bretzel, H. U. Haring, and M. Kellerer. 2002. Different role of saturated and unsaturated fatty acids in $\beta$-cell apoptosis. Biochem. Biophys. Res. Commun. 299:853-856. https://doi.org/10.1016/S0006 $-291 \mathrm{X}(02) 02752-3$.

Ferland, M.-C., M.-A. Guesthier, R. I. Cue, R. Lacroix, S. A. Burgos, D. Lefebvre, and K. M. Wade. 2018. Effect of feeding system and grain source on lactation characteristics and milk components in dairy cattle. J. Dairy Sci. 101:8572-8585. https://doi.org/10.3168/ jds.2017-13787.

Gamet, L., D. Daviaud, C. Denis-Pouxviel, C. Remesy, and J.-C. Murat. 1992. Effects of short-chain fatty acids on growth and differentiation of the human colon-cancer cell line HT29. Int. J. Cancer 52:286-289. https://doi.org/10.1002/ijc.2910520222.

Han, J., S. H. Back, J. Hur, Y.-H. Lin, R. Gildersleeve, J. Shan, C. L. Yuan, D. Krokowski, S. Wang, M. Hatzoglou, M. S. Kilberg, M. A. Sartor, and R. J. Kaufman. 2013. ER-stress-induced transcriptional regulation increases protein synthesis leading to cell death. Nat. Cell Biol. 15:481-490. https://doi.org/10.1038/ncb2738.

Harding, H. P., Y. Zhang, A. Bertolotti, H. Zeng, and D. Ron. 2000. Perk is essential for translational regulation and cell survival during the unfolded protein response. Mol. Cell 5:897-904. https://doi .org/10.1016/S1097-2765(00)80330-5.

Harding, H. P., Y. Zhang, and D. Ron. 1999. Protein translation and folding are coupled by an endoplasmic-reticulum-resident kinase. Nature 397:271-274. https://doi.org/10.1038/16729.

Hardy, S., W. El-Assaad, E. Przybytkowski, M. Joly, Y. Prentki, and Y. Langelier. 2003. Saturated fatty acid-induced apoptosis in MDAMB-231breast cancer cells. A role for cardiolipin. J. Biol. Chem. 278:31861-31870. https://doi.org/10.1074/jbc.M300190200.

Hardy, S., Y. Langelier, and M. Prentki. 2000. Oleate activates phosphatidylinositol 3-kinase and promotes proliferation and reduces apoptosis of MDA-MB-231 breast cancer cells, whereas palmitate has opposite effects. Cancer Res. 60:6353-6358.

Hayirli, A., and R. R. Grummer. 2004. Factors affecting dry matter intake prepartum in relationship to aetiology of peripartum lipid- 
related metabolic disorders: A review. Can. J. Anim. Sci. 84:337347. https://doi.org/10.4141/A03-122.

Haywood, J., and R. R. Yammani. 2016. Free fatty acid palmitate activates unfolded protein response pathway and promotes apoptosis in meniscus cells. Osteoarthritis Cartilage 24:942-945. https://doi .org/10.1016/j.joca.2015.11.020.

Hitomi, J., T. Katayama, M. Taniguchi, A. Honda, K. Imaizumi, and M. Tohyama. 2004. Apoptosis induced by endoplasmic reticulum stress depends on activation of caspase-3 via caspase-12. Neurosci. Lett. 357:127-130. https://doi.org/10.1016/j.neulet.2003.12.080.

Invernizzi, G., A. Naeem, and J. J. Loor. 2012. Short communication: Endoplasmic reticulum stress gene network expression in bovine mammary tissue during the lactation cycle. J. Dairy Sci. 95:25622566. https://doi.org/10.3168/jds.2011-4806.

Janovick, N. A., Y. R. Boisclair, and J. K. Drackley. 2011. Prepartum dietary energy intake affects metabolism and health during the periparturient period in primiparous and multiparous Holstein cows. J. Dairy Sci. 94:1385-1400. https://doi.org/10.3168/jds.2010 -3303 .

Kanekura, K., J. Ou, T. Hara, L. J. Zhu, and F. Urano. 2015. Monitoring endoplasmic reticulum membrane integrity in $\beta$-cells at the single-cell level. Mol. Endocrinol. 29:473-480. https://doi.org/10 $.1210 /$ me.2014-1260.

Katsoulieris, E., J. G. Mabley, M. Samai, I. C. Green, and P. K. Chatterjee. 2009. $\alpha$-Linolenic acid protects renal cells against palmitic acid lipotoxicity via inhibition of endoplasmic reticulum stress. Eur. J. Pharmacol. 623:107-112. https://doi.org/10.1016/j.ejphar 2009.09.015

Kristensen, N. B., A. Danfaer, and N. Agergaard. 1998. Absorption and metabolism of short-chain fatty acids in ruminants. Arch. Tierernahr. 51:165-175. https://doi.org/10.1080/17450399809381916.

Leblanc, S. 2010. Monitoring metabolic health of dairy cattle in the transition period. J. Reprod. Dev. 56(Suppl.):S29-S35. https://doi .org/10.1262/jrd.1056S29.

Listenberger, L. L., X. Han, S. E. Lewis, S. Cases, R. V. Farese Jr., D. S. Ory, and J. E. Schaffer. 2003. Triglyceride accumulation protects against fatty acid-induced lipotoxicity. Proc. Natl. Acad. Sci. USA 100:3077-3082. https://doi.org/10.1073/pnas.0630588100.

Maedler, K., G. A. Spinas, D. Dyntar, W. Moritz, N. Kaiser, and M. Y. Donath. 2001. Distinct effects of saturated and monounsaturated fatty acids on $\beta$-cell turnover and function. Diabetes 50:69-76. https://doi.org/10.2337/diabetes.50.1.69.

Matsumoto, M., M. Minami, K. Takeda, Y. Sakao, and S. Akira. 1996. Ectopic expression of CHOP (GADD153) induces apoptosis in M1 myeloblastic leukemia cells. FEBS Lett. 395:143-147. https://doi .org/10.1016/0014-5793(96)01016-2.

Maytin, E. V., M. Ubeda, J. C. Lin, and J. F. Habener. 2001. Stressinducible transcription factor $\mathrm{CHOP} /$ gadd153 induces apoptosis in mammalian cells via p38 kinase-dependent and -independent mechanisms. Exp. Cell Res. 267:193-204. https://doi.org/10.1006/ excr.2001.5248.

McIlwain, D. R., T. Berger, and T. W. Mak. 2013. Caspase function in cell death and disease. Cold Spring Harb. Perspect. Biol. 5:a008656. https://doi.org/10.1101/cshperspect.a008656.

Melendez, P., M. P. Marin, J. Robles, C. Rios, M. Duchens, and L. Archbald. 2009. Relationship between serum nonesterified fatty acids at calving and the incidence of periparturient diseases in Holstein dairy cows. Theriogenology 72:826-833. https://doi.org/ 10.1016/j.theriogenology.2009.06.001.

Nichols, K., J. Dijkstra, H. van Laar, J. J. M. Kim, J. P. Cant, and A. Bannink. 2019. Expression of genes related to energy metabolism and the unfolded protein response in dairy cow mammary cells is affected differently during dietary supplementation with energy from protein and fat. J. Dairy Sci. 102:6603-6613. https://doi.org/ $10.3168 /$ jds. $2018-15875$.

Ohara, T., and T. Mori. 2019. Antiproliferative effects of short-chain fatty acids on human colorectal cancer cells via gene expression inhibition. Anticancer Res. 39:4659-4666. https://doi.org/10.21873/ anticanres.13647.

Oyadomari, S., K. Takeda, M. Takiguchi, T. Gotoh, M. Matsumoto, I. Wada, S. Akira, E. Araki, and M. Mori. 2001. Nitric oxide-induced apoptosis in pancreatic beta cells is mediated by the endoplasmic reticulum stress pathway. Proc. Natl. Acad. Sci. USA 98:1084510850. https://doi.org/10.1073/pnas.191207498.

Patil, C., and P. Walter. 2001. Intracellular signaling from the endoplasmic reticulum to the nucleus: The unfolded protein response in yeast and mammals. Curr. Opin. Cell Biol. 13:349-355. https:/ /doi.org/10.1016/S0955-0674(00)00219-2.

Qi, L., S. Yan, R. Sheng, Y. Zhao, and X. Guo. 2014. Genes associated with milk fat and protein biosynthesis in bovine mammary epithelial cells. Asian-Australas. J. Anim. Sci. 27:414-421. https:/ /doi.org/10.5713/ajas.2013.13499.

Ron, D. 2002. Translational control in the endoplasmic reticulum stress response. J. Clin. Invest. 110:1383-1388. https://doi.org/10 .1172/JCI0216784.

Scheuner, D., B. Song, E. McEwen, C. Liu, R. Laybutt, P. Gillespie, T. Saunders, S. Bonner-Weir, and R. J. Kaufman. 2001. Translational control is required for the unfolded protein response and in vivo glucose homeostasis. Mol. Cell 7:1165-1176. https://doi.org/ 10.1016/S1097-2765(01)00265-9.

Sieber, J., M. T. Lindenmeyer, K. Kampe, K. N. Campbell, C. D. Cohen, H. Hopfer, P. Mundel, and A. W. Jehle. 2010. Regulation of podocyte survival and endoplasmic reticulum stress by fatty acids. Am. J. Physiol. Renal Physiol. 299:F821-F829. https://doi.org/10 .1152 /ajprenal.00196.2010.

Staiger, K., H. Staiger, C. Weigert, C. Haas, H. U. Haring, and M. Kellerer. 2006. Saturated, but not unsaturated, fatty acids induce apoptosis of human coronary artery endothelial cells via nuclear factor- $\mathrm{kB}$ activation. Diabetes 55:3121-3126. https://doi.org/10 $.2337 / \mathrm{db} 06-0188$.

Sun, Y., J. Luo, J. Zhu, H. Shi, J. Li, S. Qiu, P. Wang, and J. J. Loor. 2016. Effect of short-chain fatty acids on triacylglycerol accumulation, lipid droplet formation and lipogenic gene expression in goat mammary epithelial cells. Anim. Sci. J. 87:242-249. https://doi .org/10.1111/asj.12420.

Toscani, A., D. R. Soprano, and K. J. Soprano. 1988. Molecular analysis of sodium butyrate-induced growth arrest. Oncogene Res. $3: 223-238$

Van Bilsen, M., J. E. de Vries, and G. J. Van der Vusse. 1997. Longterm effects of fatty acids on cell viability and gene expression of neonatal cardiac myocytes. Prostaglandins Leukot. Essent. Fatty Acids 57:39-45. https://doi.org/10.1016/S0952-3278(97)90491-9.

Vargas-Bello-Pérez, E., J. J. Loor, and P. C. Garnsworthy. 2019. Effect of different exogenous fatty acids on the cytosolic triacylglycerol content in bovine mammary cells. Anim. Nutr. 5:202-208. https:/ /doi.org/10.1016/j.aninu.2018.09.002.

Wang, D., Y. Wei, and M. J. Pagliassotti. 2006. Saturated fatty acids promote endoplasmic reticulum stress and liver injury in rats with hepatic steatosis. Endocrinology 147:943-951. https://doi.org/10 .1210/en.2005-0570.

Wei, Y., D. Wang, F. Topczewski, and M. J. Pagliassotti. 2006. Saturated fatty acids induce endoplasmic reticulum stress and apoptosis independently of ceramide in liver cells. Am. J. Physiol. Endocrinol. Metab. 291:E275-E281. https://doi.org/10.1152/ajpendo .00644 .2005 .

Wei, Z., C. Xiao, C. Guo, X. Zhang, Y. Wang, J. Wang, Z. Yang, and Y. Fu. 2017. Sodium acetate inhibits Staphylococcus aureus internalization into bovine mammary epithelial cells by inhibiting NF- $\mathrm{B}$ activation. Microb. Pathog. 107:116-121. https://doi.org/ 10.1016/j.micpath.2017.03.030.

Weijers, R. N. M. 2012. Lipid composition of cell membranes and its relevance in type 2 diabetes mellitus. Curr. Diabetes Rev. 8:390400. https://doi.org/10.2174/157339912802083531.

Welters, H. J., M. Tadayyon, J. H. B. Scarpello, S. A. Smith, and N. G. Morgan. 2004. Mono-unsaturated fatty acids protect against $\beta$-cell apoptosis induced by saturated fatty acids, serum withdrawal or cytokine exposure. FEBS Lett. 560:103-108. https://doi.org/ 10.1016/S0014-5793(04)00079-1.

Ye, J., R. B. Rawson, R. Komuro, X. Chen, U. P. Dave, R. Prywes, M. S. Brown, and J. L. Goldstein. 2000. ER stress induces cleavage of membrane-bound ATF6 by the same proteases that process 
SREBPs. Mol. Cell 6:1355-1364. https://doi.org/10.1016/S1097 -2765(00)00133-7.

Yonekura, S., M. Tsuchiya, Y. Tokutake, M. Mizusawa, M. Nakano, M. Miyaji, H. Ishizaki, and S. Haga. 2018. The unfolded protein response is involved in both differentiation and apoptosis of bovine mammary epithelial cells. J. Dairy Sci. 101:3568-3578. https://doi .org/10.3168/jds.2017-13718.

Yonezawa, T., S. Haga, Y. Kobayashi, K. Katoh, and Y. Obara. 2009. Short-chain fatty acid signaling pathways in bovine mammary epithelial cells. Regul. Pept. 153:30-36. https://doi.org/10.1016/ j.regpep.2008.11.012.

Yonezawa, T., M. Sanosaka, S. Haga, Y. Kobayashi, K. Katoh, and Y. Obara. 2008. Regulation of uncoupling protein 2 expression by long-chain fatty acids and hormones in bovine mammary epithelial cells. Biochem. Biophys. Res. Commun. 375:280-285. https://doi .org/10.1016/j.bbrc.2008.08.021.

Yonezawa, T., S. Yonekura, Y. Kobayashi, A. Hagino, K. Katoh, and Y. Obara. 2004a. Effects of long-chain fatty acids on cytosolic triacylglycerol accumulation and lipid droplet formation in primary cultured bovine mammary epithelial cells. J. Dairy Sci. 87:25272534. https://doi.org/10.3168/jds.S0022-0302(04)73377-9.
Yonezawa, T., S. Yonekura, M. Sanosaka, A. Hagino, K. Katoh, and Y. Obara. 2004b. Octanoate stimulates cytosolic triacylglycerol accumulation and CD36 mRNA expression but inhibits Acetyl coenzyme A carboxylase activity in primary cultured bovine mammary epithelial cells. J. Dairy Res. 71:398-404. https://doi.org/10.1017/ S0022029904000408.

Yoshida, H., T. Matsui, N. Hosokawa, R. J. Kaufman, K. Nagata, and K. Mori. 2003. A time-dependent phase shift in the mammalian unfolded protein response. Dev. Cell 4:265-271. https://doi.org/10 .1016/S1534-5807(03)00022-4.

Zinszner, H., M. Kuroda, X. Wang, N. Batchvarova, R. T. Lightfoot, H. Remotti, J. L. Stevens, and D. Ron. 1998. CHOP is implicated in programmed cell death in response to impaired function of the endoplasmic reticulum. Genes Dev. 12:982-995. https://doi.org/10 $.1101 / \operatorname{gad} .12 .7 .982$

\section{ORCIDS}

Shinichi Yonekura @ \ttps://orcid.org/0000-0001-9800-1594 